\title{
Influence of hCG on inducible nitric oxide synthase gene expression in ram testicular arteries
}

\author{
Maria Matteo $^{1}$, Annalisa Rizzo ${ }^{2}$, Ettore Cicinelli ${ }^{3}$, Elvira Grandone ${ }^{4}$, Giuseppe Cardo ${ }^{5}$, \\ Donatella Colaizzo $^{4}$, Giuseppe Minoia ${ }^{2}$, Laura Castellana ${ }^{6}$, Ugo Indraccolo ${ }^{7}$, Sonia Marrocchella ${ }^{1}$, \\ Pantaleo Greco $^{1}$, Raffaele Luigi Sciorsci ${ }^{2}$ \\ ${ }^{1}$ Operative Unit of Obstetric and Gynecology, Department of Surgical Sciences, University of Foggia, Italy; \\ 2 Department of Animal Production, University of Bari, Italy; \\ $33^{\text {rd }}$ Unit of Obstetrics and Gynecology, Department of Biomedical and Human Oncological Science (DIMO), University of Bari, Italy; \\ ${ }^{4}$ Atherosclerosis and Thrombosis Unit, IRCCS "Casa Sollievo della Sofferenza", S. Giovanni Rotondo, Foggia, Italy; \\ ${ }^{5}$ Operative Unit of Urology "S. Giacomo" Hospital, Monopoli, Italy; \\ ${ }^{6}$ Department of Biomedical Sciences, University of Foggia, Italy; \\ ${ }^{7}$ Operative Unit of Gynaecology and Obstetrics of Civitanova Marche - Area Vasta 3, Marche, Italy.
}

\begin{abstract}
Summary Background. Experimental evidence suggests a relationship between the vasodilatory effect of $h C G$ and the NOS system in the testis. The influence of hCG administration on testicular vascular NOS gene expression has not been fully investigated. Objective: This study aimed to evaluate the presence of the nitric oxide syntheses gene in ram testicular arteries and the influence of hCG administration on its expression.

Materials and methods: Both testicular arteries of sixteen rams were extracted before and after i.v. administration of $5000 \mathrm{IU}$ of $\mathrm{hCG}$ or placebo. The expression of the iNOS gene was investigated by real time PCR. Data were analyzed by means of Wilcoxon and Mann-Whitney tests. A p value of $<0.05$ was considered statistically significant.

Results: PCR revealed the presence of iNOS mRNA in all basal samples but the expression of the iNOS gene was significantly reduced in all arteries obtained $24 \mathrm{~h}$ after the administration of either hCG or placebo. A significant reduction in the expression of iNOS gene was observed in the testicular arteries extracted after $24 \mathrm{~h}$ in both treated and placebo groups. On the other hand hCG stimulation did not significantly influence iNOS expression following its administration compared to a placebo. Conclusion: Ram testicular arteries express the iNOS gene but hCG stimulation did not significantly influence iNOS expression. A significant reduction in the expression of this gene was observed in the testicular arteries extracted after $24 \mathrm{~h}$ in both treated and placebo groups, suggesting that iNOS expression on the testicular artery could be influenced by the spermatic vessel ligation of the controlateral testis.
\end{abstract}

KEY WORDS: iNOS gene, Testicular artery; hCG; Ram; Intratesticular blood flow.

Submitted 17 January 2014; Accepted 15 May 2014

\section{INTRODUCTION}

Gonadotrophin treatment is capable of increasing intratesticular blood flow (1-3). Several mechanisms are described in the literature for explaining hCG induced vasodilatation in the testicular arteries (4). hCG was found to increase the expression of angiogenic factors such as vascular endothelial growth factor (VEGF) and angiopoietin 2 (ang2) $(5,6)$. hcG was also found to induce an inflammation-like response via a local increase of pro-inflammatory cytokines such as ILl by the Leydig cells $(7,8)$. Several authors have suggested that the nitric oxide syntheses (NOS) system may play a pivotal role in increasing testicular blood flow after hCG administration (9). Under basal conditions, the vasodilatory effect of NO resulted of limited importance in the testis than in other tissues but, after hCG treatment, NOS activity was found to be increased, suggesting that the increase in testicular blood flow observed in hormonally stimulated testis could be related to an increase in testicular NO synthesis (9). Although several studies have suggested a strong relationship between the vasodilatory effect of hCG and the activity of the NOS system, the influence of hCG administration on testicular vascular NOS gene expression has not been fully investigated.

The aim of this study was to evaluate the influence of exogenous hCG administration on iNOS expression in the ram testicular vasculature.

\section{MATERIAL AND METHOdS}

Testicular arteries were collected from 16 rams aged 4 to 6 years and weighing between 60 and $90 \mathrm{~kg}$ using an approach approved by the local ethical committee, in accordance with the National Research Council's (NRC) publication (10). Rams were randomly allocated into two groups: eight animals received 5000 IU of hCG i.v. (Corulon, INTERVET, Italy), eight rams (control group), received an i.v. injection of placebo. Before surgery, seda-

No conflict of interest declared. 
tion of the rams was achieved by means of an i.v. administration of $0.1 \mathrm{ml} / 20 \mathrm{~kg}$ of Xilazina cloridrato $2 \%$ (Rompum, Bayer AG, Germany) combined with an i.m. injection of $0.44 \mathrm{mg} / 10 \mathrm{~kg}$ of Atropina solfato (ATI, Italy) and of 0.04 $\mathrm{ml} / 10 \mathrm{~kg}$ of Butorfanolo (Dolorex, INTERVET, Italy).

The spermatic funiculus was isolated after a longitudinal incision of the skin and the testicular arteries were isolated and extracted from the right testis (Figure 1).

Arteries of the opposite testis were isolated and extracted from the same rams, 24 hours (h) after the administration of hCG or placebo. The vascular samples obtained were immediately incubated in tubes containing $3 \mathrm{ml}$ of Trizol Reagent (INVITROGEN, San Giuliano Milanese, Milano, Italy) and stored at $-80^{\circ} \mathrm{C}$ until the examination. Total RNA was isolated from the tissue according to the manufacturer's instructions. Phenol-phase separation was performed with gel-phase tube (Eppendendorf) in order to prevent protein contamination of the RNA. RNA was then dissolved in $20 \mu \mathrm{l}$ of RNase-free water and exposed to $55^{\circ} \mathrm{C}$ for $5 \mathrm{~min}$ to increase solubility. The RNA concentration was determined at $260 \mathrm{~nm}$ with a plate-reading spectrophotometer. For the cDNA synthesis, a mixture of $0.5 \mu \mathrm{g}$ of total RNA and $0.25 \mu \mathrm{g}$ Oligo dT (INVITROGEN) per sample was subjected to $65^{\circ} \mathrm{C}$ for 5 min to promote primer annealing. A volume of $20 \mu \mathrm{l}$ of RT reaction solution containing $200 \mathrm{U}$ of Moloney murine leukimia virus reverse transcriptase and $8 \mu \mathrm{l}$ of RT master mix composed of $1 \times$ RT buffer, $25 \mathrm{mM}$ dTT and $1.25 \mathrm{mM}$ dNTP was incubated at $37^{\circ} \mathrm{C}$ for $70 \mathrm{~min}$. The quantity iNOS gene mRNA expression was evaluated by the ABI 7700TM quantitative real time PCR system (Applied Biosystems, Warrington, UK) and compared to the Ovis aries housekeeping $\beta$ Actin gene. The MGB probes used for quantification of the targets and endogenous controls were designed according to the TaqMan technology (Applied Byosistems) employing the Primer Express (Applied Biosystems) computer software using published gene sequences. The fluorescent signal from the dye 6carboxyfluorescein (6-FAM) at the 5' end of the probe was quenched by another fluorochrome, VIC, at the $3^{\prime}$ end. The quenching effect terminated as the probe was cleaved due to the $5^{\prime}$ exonuclease activity of the amplitaq Gold (Applied Biosystems) enzyme and a fluorescent signal was emitted. The emittance resulted proportional to the amount of amplified product, until it reached the lag phase of the PCR. A threshold value set above the baseline reflected the average change in emittance during the first PCR cycles. The real-time PCR reactions were performed on plates using adhesive seals as covers. To quantify the mRNA levels we used a relative standard curve method in which the untreated control was used as an
Figure 1.

Testicular artery isolated and extracted from the spermatic funiculum of the ram.

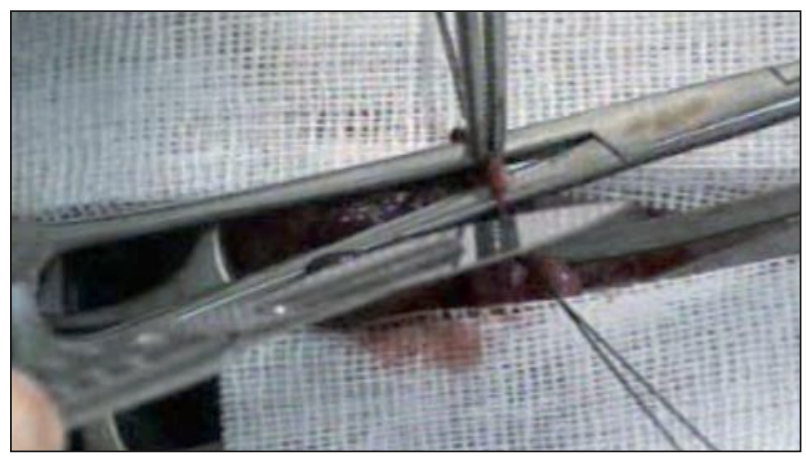

appropriate calibrator. The sequences of the primers and probe are shown in Table 1. Each sample contained: $3 \mu \mathrm{l}$ of cDNA, Taqman Universal PCR Master Mix (12.5 $\mu \mathrm{l})$, $\beta$ Actin primers $900 \mathrm{nM}$ and probe $200 \mathrm{nM}$, iNOS primers $900 \mathrm{nM}$ and probe $200 \mathrm{nM}$ and RNAse-free water to a volume of $25 \mu \mathrm{l}$. Amplification was performed for $10 \mathrm{~min}$ at $95^{\circ} \mathrm{C}, 45$ cycles of 15 seconds at $95^{\circ} \mathrm{C}, 60$ seconds at $60^{\circ} \mathrm{C}$. Gene expression levels were calculated using standard curves generated by serial dilutions of cDNA. A strong correlation between PCR efficiency of the internal control ( $\beta$ Actin) and the target allowed the use of the $\Delta \Delta \mathrm{Ct}$-method (Applied Biosystems) to quantify comparable mRNA levels (11). Three independent analyses were performed with replicates. Data were analyzed by means of Wilcoxon and Mann-Whitney tests and a $p$ value of $<0.05$ was considered statistically significant. Results were expressed as means + standard deviation.

\section{Results}

The real time PCR revealed the expression of iNOS mRNA in samples obtained from all the 16 rams, without surgical complications.

The descriptive statistics of the data are reported in Table 2.

Table 1.

Quantitative real time PCR system. Sequences of the primers and probe used to evaluate iNOS gene MRNA expression.

\begin{tabular}{|ll|}
\hline PRIMERS $\beta$ ACTIN & PRIMERS INOS \\
\hline FW: TCAAGATCATCGCGCCC & Rev: GCCGCCAATCCACACG \\
FW: CAACATCAGGTCGGCCATC & Rev: AGTCATGCTTCCCATCGCT \\
\hline PROBE $\beta$ ACTIN MGB (VIC): & PROBE INOS MGB (FAM): \\
CTGAGCGCAAGTAC & CGTGTTCCCCAGC \\
\hline
\end{tabular}

Table 1.

Descriptive Statistics: The mean and median iNOS mRNA expression in the arteries extracted after $24 \mathrm{~h}$ in both the treated and placebo groups

\begin{tabular}{|l|c|c|c|c|r|r|}
\hline & N & Mean & Std. Deviation & Minimum & Maximum & $\begin{array}{c}\text { Percentiles } \\
\text { 50th median) }\end{array}$ \\
\hline Basal 1 & 8 & 1.00 & 0.000 & 1.00 & 1.00 & 1.00 \\
24h trattati & 8 & 0.34 & 0,39 & 0.01 & 1.08 & 0.05 \\
24h placebo & 8 & 0.36 & 0.28 & 0.03 & 0.13 & 0.13 \\
\hline
\end{tabular}


The mean and median iNOS mRNA expression in the arteries extracted after $24 \mathrm{~h}$ in both the treated and placebo groups were reduced compared to the basal samples. Moreover the mean and median in the group exposed to 24 hours of treatment were lower than those in the group exposed to 24 hours of placebo. The Wilcoxon rank test was performed to evaluate differences both between basal versus $24 \mathrm{~h}$ treated samples and basal versus $24 \mathrm{~h}$ placebo. We found a significant $(\mathrm{p}<0.05)$ decrease in the iNOS mRNA expression in the arteries extracted after $24 \mathrm{~h}$ both when we compared basal versus $24 \mathrm{~h}$ treated samples $(\mathrm{p}=$ 0.017 ) and basal versus $24 \mathrm{~h}$ placebo samples ( $\mathrm{p}=0.012$ ). The Mann-Whitney test was performed to evaluate differences between treated and controls after $24 \mathrm{~h}$, and no significant difference was found ( $\mathrm{p}>0.05$ ).

\section{Discussion}

The study demonstrates that the iNOS gene is expressed in the testicular artery of the ram

and that iNOS activity is not influenced by i.v. administration of hCG. In fact the effects on iNOS gene expression observed after $24 \mathrm{~h}$ in the hCG group did not differ from that observed in the placebo group (Figure 2).

Several reports have been published concerning the role of the NOS system in the male reproductive tract (12-

Figure 2.

iNOS MRNA expression in arteries obtained after 24 hours from the $h C G$ and placebo groups.

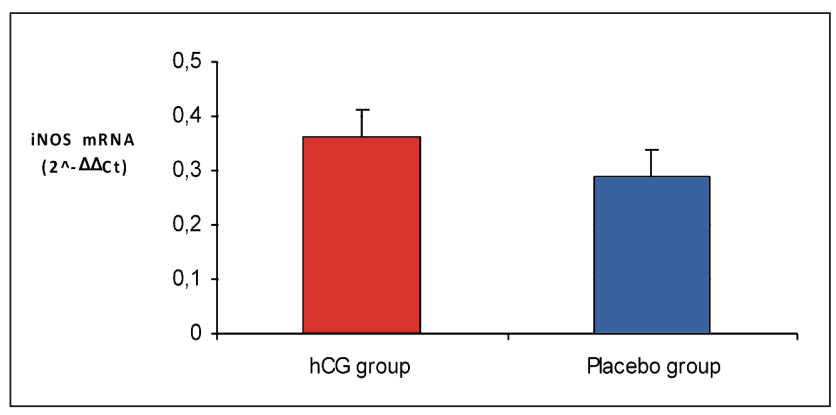

Figure 3.

iNOS MRNA expression before and 24 hours after the administration of hCG or placebo.

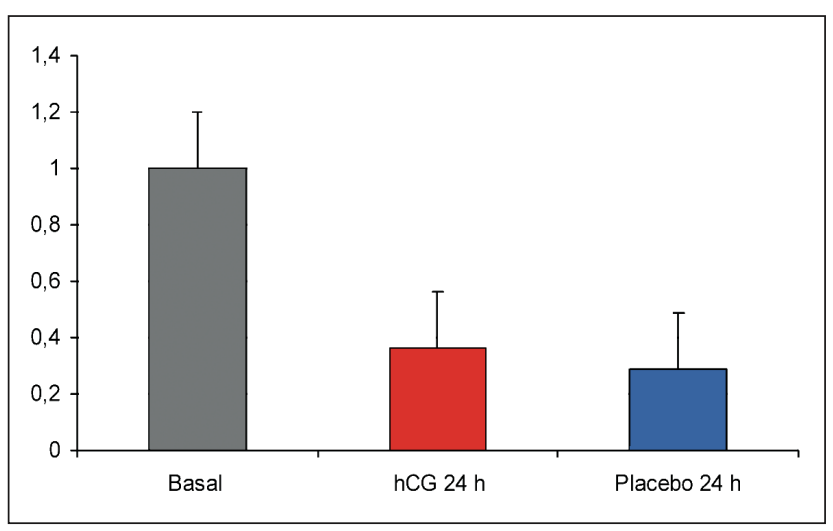

14). NO was found to be of importance for sperm quality and sperm fertilization potential (15-18) and to influence the testicular vascular relaxation by increasing cGMP levels (12). However, under basal condition, in the unstimulated intact testis only low levels of NOS activity have been detected $(21,22)$. Accordingly the vasoconstrictor response to L-NAME NOS inhibition is weak (5) and acetylcholine does not increase testicular blood flow $(19,20)$.

Conversely, experimental evidence suggests that, after hormonal stimulation, the NOS system could play a role in the regulation of the testicular vascular system since the intensity of NADPH staining of the testicular artery, known to be directly correlated with the NOS activity, was found to increase after hCG treatment $(9,23,24)$. Furthermore treatment with L-NAME NOS was found to increase vascular resistance in the testis after stimulation with hCG (9). Notably we did not observe any difference in the iNOS gene expression of the testicular artery extracted $24 \mathrm{~h}$ after hCG administration, compared with the placebo group (means $0.36+0.28$ and $0.29+0.23$ respectively) (Figure 2 ).

These findings suggest that hCG treatment does not have a direct effect on iNOS activity in the testicular artery but the effects on testicular blood flow could be mediated by other factors. Several reports could support this discrepancy. Firstly, hCG treatment is known to induce an increase in testicular blood flow, but this effect is not observed in Leydig cell-depleted animals, suggesting that the effect on blood flow is mediated by the increase in sex steroid secretion via stimulation of the Leydig cells (2).

Secondly, studies have reported that hCG treatment results in local secretion within the testis of potent vasoconstrictors such as serotonin and endothelin- 1 and that the increase in NO synthesis occurs to balance the effects of such local vasoconstrictors $(25,26)$. Moreover, other authors have speculated upon the presence of a permeability-inhibiting factor in testicular microvessels that is down regulated by hCG $(7,27)$.

Finally, hCG was found to increase the expression of angiogenic factors such as VEGF (6) and the ang2, which are associated with an increase in vascular permeability $(5,6)$. In a previous report we demonstrated the presence of Thromboxane A2 (TXA2) receptors, known as TP $\alpha$ receptor, in the testicular artery of the ram. In addition, our results showed that TP $\alpha$ receptor gene expression was completely suppressed in all samples 24 hours after i.v. administration of 5000 IU of hCG, suggesting that a down regulation of TXA2 activity could be an additional mechanism explaining the vasodilatory effect of hCG in the testis (28).

This study support the hypothesis that the testicular vascular relaxation observed after hCG administration is not related to a direct effect of hCG on the testicular NOS system, but could be mediated by the up and down regulation of the inhibiting and stimulating factors described above. Unexpectedly, a significant reduction in iNOS gene expression was observed in the testicular arteries extracted after $24 \mathrm{~h}$ in both groups (Figure 3), suggesting that the decrease in iNOS activity could be related to the spermatic vessel ligation of the contralateral testis.

Only a limited number of studies have reported the effect 
of spermatic vessel ligation (named Fowler-Stephens maneuver) on iNOS expression and NO levels in the ipsilateral and contralateral testis, although it is the most popular method in the surgical management of high testes (29-31).

These studies showed an increase in NO levels and in iNOS immunostaining in both testes, whereas moderate iNOS immunostaining expression and germ cell apoptosis were observed in the contralateral testis 24 hours after ligation (31).

These findings are partially in agreement with the results of the present study which point to potentially important physiological implications of the NOS system in the physiopathology of testicular germ cell apoptosis observed after the Fowler Stephens maneuver. Moreover, it may be supposed that an ipsilateral flow obstruction (as it happens during testicular torsion) may cause a contralateral vascular injury (32).

\section{Conclusion}

The ram testicular artery expresses the iNOS gene but its expression and functional activity is not directly influenced by hCG stimulation. Further investigations are needed to confirm these results and to elucidate the functional role and the mechanisms involved in the regulation of the testicular vascular NOS system.

\section{REFERENCES}

1. Matteo M, Cicinelli E, Baldini D, et al. Influence of human menopausal gonadotrophin treatment on testicular blood flow and on seminal plasma nitric oxide levels in infertile males Int J Androl. 2006; 29:441.

2. Bergh A, Damber JE, et al. Does follicle-stimulating hormone or pregnant mare serum gonadotrophin influence testicular blood flow in rats? Int J Androl. 1992; 15:365.

3. Causio F, Matteo M, Cicinelli E, et al. Variation of intratesticular blood flow in response to urinary follicle-stimulating hormone treatment in men with severe oligoteratoasthenozoospermia Fertil Steril. 2002; 78:1133.

4. Damber J.E, Bergh A, Fagrell B, et al. Testicular microcirculation in the rat studied by videophotometric capillaroscopy, fluorescence microscopy and laser Doppler flowmetry Acta Physiol Scand. 1986; 126:371.

5. Rudolfsson SH, Johansson A, Franck Lissbrandt I, et al. Localized expression of angiopoietin 1 and 2 may explain unique characteristics of the rat testicular microvasculature Biol Reprod. 2003; 69:1231.

6. Rudolfsson SH, Wikstrom P, Jonsson A, et al. Hormonal regulation and functional role of vascular endothelial growth factor $a$ in the rat testis Biol Reprod. 2004; 70:340.

7. Bergh A, Damber JE, Hjertkvist M. Human chorionic gonadotrophin-induced testicular inflammation may be related to increased sensitivity to interleukin-1 Int J Androl. 1996; 19:229.

8. Assmus M, Svechnikov K, von Euler M, et al. Single subcutaneous administration of chorionic gonadotropin to rats induces a rapid and transient increase in testicular expression of pro-inflammatory cytokines Pediatr Res. 2005; 57:896.

9. Lissbrant E, Lofmark U, Collin O, Bergh A. Is nitric oxide involved in the regulation of the rat testicular vasculature? Biol Reprod. 1997; 56:1221.

10. NRC Guide for the Care and Use of Agricultural Animals in Agricultural Research and Teaching. Consortium for Developing a Guide for the Care and Use of Agricultural Animals in Agricultural Research and Teaching. Champaign, IL, 1988.

11. Livak JK, Schmittgen TD. Analysis of relative gene expression data using real-time quantitative PCR and the 2(-Delta Delta C (T)) Methods. 2001; 25:402.

12. Middendorff R, Muller D, Wichers S, et al. Evidence for production and functional activity of nitric oxide in seminiferous tubules and blood vessels of the human testis J Clin Endocrinol Metab. 1997; 82:4154.

13. Battaglia C, Giulini S, Regnani $G$, et al. Seminal plasma nitrite/nitrate and intratesticular Doppler flow in fertile and infertile subjects Hum Reprod. 2000; 15:2554.

14. Zini A, O'Bryan M.K, Magid M.S, Schlegel PN. Immunohistochemical localization of endothelial nitric oxide synthase in human testis, epididymis, and vas deferens suggests a possible role for nitric oxide in spermatogenesis, sperm maturation, and programmed cell death Biol Reprod. 1996; 55:935.

15. Zhang $H$, Zheng RL. Possible role of nitric oxide on fertile and asthenozoospermic infertile human sperm functions Free Radic Res. 1996; 25:347.

16. Herrero MB, Viggiano JM, Perez-Martinez S, et al. Evidence that nitric oxide synthase is involved in progesterone-induced acrosomal exocytosis in mouse spermatozoa Reprod Fertil Dev. 1997; 9:433.

17. O'Bryan MK, Zini A, Cheng CY, Schlegel PN. Human sperm endothelial nitric oxide synthase expression: correlation with sperm motility Fertil Steril. 1998; 70:1143.

18. Sengoku K, Tamate K, Yoshida T, et al. Effects of low concentrations of nitric oxide on the zona pellucida binding ability of human spermatozoa Fertil Steril. 1998; 69:522.

[19. Noordhuizen-Stassen EN, Beijer G, Wensing CJ. The effect of norepinephrine, isoprenaline and acetylcholine on testicular and epididymal circulation in the pig Int J Androl. 1983; 6:44.

20. Whittle BJ. Nitric oxide in physiology and pathology Histochem J. 1995; 27:727.

21. Burnett AL, Ricker DD, Chamness SL, et al. Localization of nitric oxide synthase in the reproductive organ of the male rat Biol Reprod. 1995; 52:1.

22. Ehren I, Adolfsson J, Wiklund NP. Nitric oxide synthase activity in the human urogenital tract Urol Res. 1994; 22:287.

23. Brendt DS, Hwang PM, Synder S.H. Localization of nitric oxide synthase indicating a neuronal role for nitric oxide Nature. 1990; 347:768.

24. Hope BT, Michael GJ, Knigge KM, Vincent S. Neuronal NADPH diaphorase is a nitric oxide synthase Proc Natl Acad Sci USA 1991; 88:2811.

25. Collin O, Damber JE, Bergh A. 5-Hydroyxytryptamine a local regulator of testicular blood flow and vasomotion in rats J Reprod Fertil. 1996; 106:17.

26. Collin O, Damber JE, Bergh A. Effects of endothelin-1 on the rat testicular vasculature J Androl. 1996; 17:360.

27. Hjertkvist M, Bergh A. The time response and magnitude of hCG induced vascular changes are different in scrotal and abdominal testes Int J Androl. 1993; 16:63. 
28. Matteo M, Cicinelli E, Sciorsci RL, et al. Expression and hormonal modulation of the thromboxane A2 receptor gene in mammalian testicular arteries Fertil Steril 2006; 85:1276.

29. Levy DA, Abdul-Karim FW, Miraldi F, Elder JS. Effect of human chorionic

gonadotropin before spermatic vessel ligation in the prepubertal rat testis J Urol. 1995; 154:738.

30. Taneli F, Vatansever S, Ulman C, Giray G, Genc A, Tanel C.
Pre-ischemic administration of nitric oxide synthase inhibitors reduced germ cell apoptosis after spermatic vessel ligation in the rat testis Urol Int. 2005; 75:70.

31. Taneli F, Vatansever S, Ulman C, et al. The effect of spermatic vessel ligation on testicular nitric oxide levels and germ cell-specific apoptosis in rat testis Acta Histochem. 2005; 106:459.

32. Ozkan KU, Küçükaydin $M$, Muhtaroglu S, Kontas O. Evaluation of contralateral testicular damage after unilateral testicular torsion by serum inhibin B levels J Pediatr Surg. 2001; 36:1050.

\section{Correspondence}

Maria Matteo, MD, PhD (Corresponding Author)

maria.matteo@unifg.it

Sonia Marrocchella, MD

Pantaleo Greco, MD

Institute of Obstetrics and Gynecology

Department of Medical and Surgical Sciences,

University of Foggia, Viale Pinto 71100 Foggia, Italy

Annalisa Rizzo, MD

Giuseppe Minoia, MD

Raffaele Luigi Sciorsci, MD

Department of Animal Production, University of Bari, Bari, Italy

Ettore Cicinelli, MD

$3^{\text {rd }}$ Unit of Obstetrics and Gynecology,

Department of Biomedical and Human Oncological Science (DIMO)

University of Bari, Bari, Italy

Elvira Grandone, MD

Donatella Colaizzo, MD

Atherosclerosis and Thrombosis Unit,

IRCCS "Casa Sollievo della Sofferenza"

S. Giovanni Rotondo, Foggia, Italy

Giuseppe Cardo, MD

Operative Unit of Urology "S. Giacomo" Hospital, Monopoli, Italy

Laura Castellana, MD

Department of Biomedical Sciences, University of Foggia, Foggia, Italy

Ugo Indraccolo, MD

Operative Unit of Gynaecology and Obstetrics of Civitanova Marche -

Area Vasta 3 - Civitanova Marche, Italy 